\title{
Can oil shocks explain asymmetries in the US Business Cycle?
}

\author{
Michael P. Clements \\ Department of Economics, \\ University of Warwick, \\ Coventry, CV4 7AL. \\ and
}

Hans-Martin Krolzig*

Department of Economics, and Nuffield College, Manor Road Building, Oxford, OX1 3UQ.

Hans-Martin.Krolzig@nuf.ox.ac.uk

November 30, 2000

\begin{abstract}
We consider whether oil prices can account for business cycle asymmetries. We test for asymmetries based on the Markov switching autoregressive model popularized by Hamilton (1989), using the tests devised by Clements and Krolzig (2000). We select the transformation of the oil price of Lee, Ni and Ratti (1995), based on a linear analysis of the relationship between output growth and the oil price employing PcGets. We find overwhelming evidence against the conventional wisdom that recessions are more violent than expansions: while some of violence of economic downturns can be attributed to dramatic changes in the price of oil, post-War US economic growth is characterized by the steepness of expansions.
\end{abstract}

JEL classification: E32, C32, E24.

Keywords: Oil prices, Business cycle asymmetries, Markov-switching models.

\section{Introduction}

A number of recent papers have explored the relationship between oil prices and the macroeconomy. Hooker (1996) shows that the linear relationship between oil prices and output proposed by Hamilton (1983) does not appear to hold from 1973 onwards. He also casts doubt on the asymmetric relationship proposed by Mork (1989): that output responds negatively to oil price increases but is unaffected by oil price declines. Hamilton (1996) suggests that output should be related to the net increase in real oil prices over the previous year, and constructs a variable that is the maximum of the percentage change in the oil price in the current quarter over the previous year's high, and zero. Thus, increases in the price of oil which simply reverse previous (within the preceding year) declines do not depress output growth: see figure 1. Recently, Hamilton (2000) has used a flexible approach to characterize the appropriate non-linear transform of the oil price, and finds that the transformation that gives the net increase in the oil price can not be rejected (but nor can a number of other transformations).

Raymond and Rich (1997) have investigated the relationship between oil prices and the macroeconomy by including the net increase in the oil price (NOPI) in the two-regime Markov-Switching model of US output growth of Hamilton (1989) for the period 1952 - 1999. Of interest is whether the recurrent shifts between expansion (high growth) and contraction (low growth, or declines in output) suggested by the Markov-switching model remain a feature of post War US output once an allowance

${ }^{*}$ Financial support from the UK Economic and Social Research Council under grant L138251009 is gratefully acknowledged by both authors. All the computations reported in this paper were carried out using the MSVAR package for Ox (see Krolzig, 1998, and Doornik, 1999) and PcGets of David F. Hendry and Hans-Martin Krolzig. 
has been made for the effects of oil price increases. A plausible hypothesis is that increases in the oil price may explain (at least part of) the low trend growth states, so that the model with oil prices no longer generates recessions that match the NBER dating. They conclude that 'while the behavior of oil prices has been a contributing factor to the mean of low growth phases of output, movements in oil prices generally have not been a principal determinant in the historical incidence of these phases...' (p. 196). They also allow the oil price to affect the transition probabilities of the states directly, following the approach of Diebold, Rudebusch and Sichel (1993), Filardo (1994) and Filardo and Gordon (1998), but find little support for this channel of influence.

Our approach follows that of Raymond and Rich (1997) but we ask a different question: are oil prices responsible for business cycle asymmetries? Some authors appear to have assumed that the finding that a non-linear model (as opposed to a linear model) characterizes the data of itself suggests business cycle asymmetries: see e.g., Luukkonen and Teräsvirta (1991). The argument is that models such as self-exciting threshold autoregressive models (see, e.g., Tong and Lim, 1980, Tong, 1995), and smooth transition autoregressive model (see, e.g., Luukkonen, Saikkonen and Teräsvirta, 1988, Teräsvirta and Anderson, 1992) have different dynamic structures across regimes so that the probability of remaining in a regime, once entered, may not be equal across regimes. Different 'exit' probabilities suggest different durations, and therefore asymmetry on the definition due to Sichel (1993, p. 224), that an asymmetric cycle is 'one in which some phase of the cycle is different from the mirror image of the opposite phase'.

Clements and Krolzig (2000) show Markov-Switching autoregressive (MS-AR) models are able to generate symmetric cycles, or cycles that exhibit one (or more) of the different types of steepness, deepness, and sharpness asymmetries discussed in the literature. These asymmetries are typically tested for using separate non-parametric tests, but restrictions on the parameters of the MS-AR model can be derived, which, if they hold, would rule out a particular type of asymmetry. Wald tests of these restrictions are then formulated. The tests of Clements and Krolzig (2000) are able to detect asymmetries in the propagation mechanisms of shocks, or first-moment asymmetries, while non-parametric tests based on the coefficient of skewness of the (first-differenced) detrended series are unable to discriminate between first-moment asymmetries and asymmetries in the shocks. The parametric tests can also be applied to MS-AR models with exogenous variables, to see whether such variables account for asymmetries in the observed output growth series.

We use the data set in Hamilton (2000) ${ }^{1}$. As well as NOPI (and a variant that calculates the maximum relative to the previous three years, N3OPI), Hamilton also makes available three other oil price series that have recently been used to explain US output growth. One is the growth rate of the real oil price (DRoil), so that linear models employing this variable will not allow for asymmetric responses to increases and decreases. The other two are a time series of exogenous supply shocks (Quant), and a variable used by Lee et al. (1995) (LNR), that is, the real increase in the oil price adjusted for the variability in the real oil price (see Lee et al., 1995, for details). We base a decision as to which transformation of the oil price to use on the linear relationship between output growth and oil prices. This can be done simply and efficiently using David F. Hendry and Hans-Martin Krolzig's PcGets program, as described in section 3. On the basis of this, we select the LNR variable to gauge the impact of oil prices on business cycle asymmetries, though it turns out that the results are relatively robust to the transformation.

The plan of the paper is as follows. Section 2 briefly reviews notions of business cycle asymmetries, non-parametric tests of these features, and the parametric tests proposed by Clements and Krolzig (2000): the latter paper gives a fuller discussion of the material in this section. Section 3 discusses the

\footnotetext{
${ }^{1}$ Freely available from http: // weber. ucsd. edu/ jhamilto
} 
application of these tests to univariate and multivariate variants of the Hamilton model augmented with LNR and other oil price transforms. Section 4 concludes.

\section{Testing for business cycle asymmetries}

\subsection{Steepness, deepness and sharpness (SDS)}

There has been much interest in whether macroeconomic variables behave differently over the phases of the business cycle. The conventional wisdom as expressed by Mitchell (1927, p. 290) is that 'the most violent declines exceed the most considerable advances [...] Business contractions appear to be a briefer and more violent process than business expansions'.

Sichel (1993) distinguishes two types of business cycle asymmetry: 'steepness' and 'deepness'. The former relates to whether contractions are steeper (or less steep) than expansions, the latter to whether the amplitude of troughs differs from that of peaks. He suggests a test of deepness based on the coefficient of skewness calculated for the detrended series. Deepness of contractions will show up as negative skewness, since it implies that the average deviation of observations below the mean will exceed that of observations above the mean. Steepness implies skewness in the first difference of the detrended series. Positive skewness suggests steepness of expansions: increases should be larger, though less frequent, than decreases. On the basis of these tests, deepness is found to characterize quarterly post-War US unemployment and industrial production, with weaker evidence for GNP, while only unemployment (of the three) appears to exhibit steepness.

Because the observations on the detrended series typically exhibit some dependence, Sichel (1993, p. 227-8) calculates an asymptotically heteroscedastic and serial correlation consistent standard error for the coefficient of skewness using the Newey and West (1987) procedure.

Sharpness or turning point asymmetry (see McQueen and Thorley (1993)), results if, e.g., troughs are 'sharp' and peaks more rounded. Sharpness can be tested by considering the magnitude of growth rate changes around NBER-dated peaks and troughs. The mean absolute changes are calculated for peaks and troughs separately, and the test for asymmetry is based on rejecting the null of the population mean changes in the variable at peaks and troughs being equal. Alternatively, a testing procedure can be based on the transition probabilities of a second-order three state Markov chain.

Formally, then steepness, deepness and sharpness (SDS) can be defined as follows, letting $\left\{x_{t}\right\}$ denote the detrended series:

Definition 1. Deepness. Sichel (1993). The process $\left\{x_{t}\right\}$ is said to be non-deep (non-tall) iff $x_{t}$ is not skewed:

$$
\mathrm{E}\left[\left(x_{t}-\mu_{x}\right)^{3}\right]=0 .
$$

Analogously we can define steepness as skewness of the differences:

Definition 2. Steepness. Sichel (1993). The process $\left\{x_{t}\right\}$ is said to be non-steep iff $\Delta x_{t}$ is not skewed:

$$
\mathrm{E}\left[\left(\Delta x_{t}\right)^{3}\right]=0
$$

Negative skewness of $x_{t}$ and $\Delta x_{t}$ indicates steep and deep contractions. The opposite case are tall $\left(\mathrm{E}\left[\left(x_{t}-\mu_{x}\right)^{3}\right]>0\right)$ and steep $\left(\Delta x_{t}\right.$ positively skewed) expansions, although all combinations are possible.

Definition 3. Sharpness. McQueen and Thorley (1993). The process $\left\{x_{t}\right\}$ is said to be non-sharp iff the transition probabilities to and from the two outer regimes are identical:

$$
p_{m 1}=p_{m M} \text { and } p_{1 m}=p_{M m}, \text { for all } m \neq 1, M ; \text { and } p_{1 M}=p_{M 1},
$$


where $M$ denotes the number of regimes.

In a two-regime model, for example, non-sharpness implies that $p_{12}=p_{21}$. In a three-regime model, it requires $p_{13}=p_{31}$ and in addition $p_{12}=p_{32}$ and $p_{21}=p_{23}$.

\subsection{Asymmetries in MS-AR processes}

We can write the MS-AR model as:

$$
x_{t}-\mu\left(s_{t}\right)=\sum_{k=1}^{p} \alpha_{k}\left(x_{t-k}-\mu\left(s_{t-k}\right)\right)+u_{t}, \quad u_{t} \mid s_{t} \sim \operatorname{NID}\left(0, \sigma^{2}\right) .
$$

This formulation exhibits Markov-switching in the Mean of the process (and which we label as $\operatorname{MS} M(M)-\operatorname{AR}(p))$, so that $\mu\left(s_{t}\right)$ takes on one of the values $\mu_{1}<\ldots<\mu_{M}$, depending on which of the $M$ regimes the process is in. The Markov chain is ergodic, irreducible, and there does not exist an absorbing state, i.e., $\bar{\xi}_{m} \in(0,1)$ for all $m=1, \ldots, M$, where $\bar{\xi}_{m}$ is the ergodic or unconditional probability of regime $m$. The findings of Raymond and Rich (1997) support the assumption of time-invariant transition probabilities:

$$
p_{i j}=\operatorname{prob}\left(s_{t+1}=j \mid s_{t}=i\right), \quad \sum_{j=1}^{M} p_{i j}=1 \quad \forall i, j \in\{1, \ldots, M\} .
$$

Clements and Krolzig (2000) establish the following propositions concerning the restrictions on the parameter space of the MSM-AR model that correspond to the concepts of steepness and deepness (the restrictions implied by sharpness follow immediately):

Proposition 1. An $\operatorname{MSM}(M)-A R(p)$ process is non-deep iff

$$
\sum_{m=1}^{M} \bar{\xi}_{m}\left(\mu_{m}-\mu_{x}\right)^{3}=0
$$

where $\bar{\xi}_{m}$ is the unconditional probability of regime $m$, and $\mu_{x}=\sum_{i} \mu_{i} \bar{\xi}_{i}$ is the unconditional mean of $x_{t}$.

Example 1. Consider the case of two regimes. The $M S M(2)-A R(p)$ process can be written as the sum of two independent processes: $x_{t}-\mu_{x}=\mu_{t}+z_{t}$, where $\mathrm{E}\left[\mu_{t}\right]=\mathrm{E}\left[z_{t}\right]=0$. While the process $z_{t}=$ $\sum_{j=1}^{p} \alpha_{j} z_{t-j}+u_{t}$ is Gaussian, $\mu_{t}$ represents the contribution of the Markov chain, $\mu_{t}=\left(\mu_{1}-\mu_{2}\right) \zeta_{t}$, with $\zeta_{t}=\xi_{1 t}-\bar{\xi}_{1}$, which equals $1-\bar{\xi}_{1}$ if the regime is 1 and $-\bar{\xi}_{1}$ otherwise. Invoking proposition 1, the skewness of the Markov chain is given by:

$$
\mathrm{E}\left[\mu_{t}^{3}\right]=\sum_{m=1}^{2} \bar{\xi}_{m}\left(\mu_{m}-\mu_{x}\right)^{3}=\bar{\xi}_{1}\left(\mu_{1}-\mu_{x}\right)^{3}+\left(1-\bar{\xi}_{1}\right)\left(\mu_{2}-\mu_{x}\right)^{3}
$$

where $\mu_{x}=\bar{\xi}_{1} \mu_{1}+\left(1-\bar{\xi}_{1}\right) \mu_{2}$ and $\bar{\xi}_{1}=p_{21} /\left(p_{12}+p_{21}\right)$ is the unconditional probability of regime one. Thus:

$$
\mathrm{E}\left[\mu_{t}^{3}\right]=\bar{\xi}_{1}\left(1-\bar{\xi}_{1}\right)\left[1-2 \bar{\xi}_{1}\right]\left(\mu_{1}-\mu_{2}\right)^{3} .
$$

As the Markov-switching model implies that $\mu_{1} \neq \mu_{2}$ and $\bar{\xi}_{1} \in(0,1)$, non-deepness, $\mathrm{E}\left[\mu_{t}^{3}\right]=0$, requires that $\bar{\xi}_{1}=0.5$. Hence the matrix of transition probabilities must be symmetric, $p_{12}=p_{21}$. This also implies that the regime-conditional means $\mu_{1}$ and $\mu_{2}$ are equidistant to the unconditional mean $\mu_{y}$.

Hence, in the case of two regimes we can test for non-deepness by testing the hypothesis $p_{12}=p_{21}$. This is equivalent to the test of non-sharpness. For processes with $M>2$ we propose to test for non-deepness conditional on $\mu_{x}$ and the $\bar{\xi}_{m}$. 
Proposition 2. An MSM(M)-AR(p) process is non-steep if the size of the jumps, $\mu_{j}-\mu_{i}$, satisfies the following condition:

$$
\sum_{i=1}^{M-1} \sum_{j=i+1}^{M}\left(\bar{\xi}_{i} p_{i j}-\bar{\xi}_{j} p_{j i}\right)\left[\mu_{j}-\mu_{i}\right]^{3}=0 .
$$

Symmetry of the matrix of transition parameters (which is stronger than the definition of sharpness) is sufficient but not necessary for non-steepness.

In contrast to deepness, the condition for steepness depends not only on the ergodic probabilities, $\bar{\xi}_{j}$, but also directly on the transition parameters.

Example 2. In an $M S M(2)-A R(p)$ process, condition (4) gives:

$$
\mathrm{E}\left[\Delta \mu_{t}^{3}\right]=\left(\bar{\xi}_{1} p_{12}-\bar{\xi}_{2} p_{21}\right)\left[\mu_{2}-\mu_{1}\right]^{3} .
$$

This is necessarily equal to zero, so a two-regime Markov-switching model is always non-steep. Since $\bar{\xi}_{1} / \bar{\xi}_{2}=p_{21} / p_{12}$, we have that $\bar{\xi}_{1} p_{12}-\bar{\xi}_{2} p_{21}=0$ and hence $\mathrm{E}\left[\Delta \mu_{t}^{3}\right]=0$.

Two-regime MS models are incapable of generating steepness asymmetries. In the next section this is shown to have important implications for testing for business cycle asymmetries in MS models.

\section{Oil prices and the US Business Cycle}

\subsection{Selecting oil price transforms under linearity}

We select the transformation of the oil price that gives the best fit in an autoregressive-distributed lag (ADL) model. Specifically, with the output growth as the dependent variable, we begin with a general unrestricted model containing four of its lags, and lags from one to four on each of the five oil price variables. We then test down, with the aim of arriving at a simple model, which might indicate that a particular oil price variable is 'best'. However, because the oil price variables are highly collinear, as is apparent from figure 1, the final model may depend on the precise way in which the successive rounds of simplifications are carried out, and on the order in which 'insignificant' variables (or groups of variables) are deleted. We use David F. Hendry and Hans-Martin Krolzig's PcGets to automate the simplification procedure. By searching all the possible paths, and then comparing all the candidate models so obtained, the problem of path-dependence is solved: see Krolzig and Hendry (2000) for details of the algorithms.

The program can be used in several modes. Initially, we employed the 'outlier correction' facility, which automatically adds impulse dummies to the general model to correct for outliers, before simplifying. Eight dummy variables were selected. The final model retained all the dummy variables, and included lags 1 and 3 of the dependent variable, lags 1, 3 and 4 of LNR , and lag 2 of Quant. The significance of the eight dummies in the general model and the final specification could be interpreted as suggesting the linear relationship is inadequate, possibly pointing toward a non-linear model, although other explanations, such as omitted variables, are at least as plausible. Omitting the outlier dummies from the general model resulted in a similar, though simpler final model, in which the second lag of Quant dropped out:

$$
x_{t}=\underset{(8.39)}{0.88}+\underset{(2.99)}{0.21} x_{t-1}-\underset{(3.86)}{0.42} \mathrm{LNR}_{t-3}-\underset{(4.07)}{0.47} \mathrm{LNR}_{t-4},
$$

where $x_{t}$ is output growth (the difference of the natural logarithm of the GNP series, multiplied by one hundred). This is similar to eqn (3.6) of Hamilton (2000), who explains the interpretation of the LNR coefficients. 


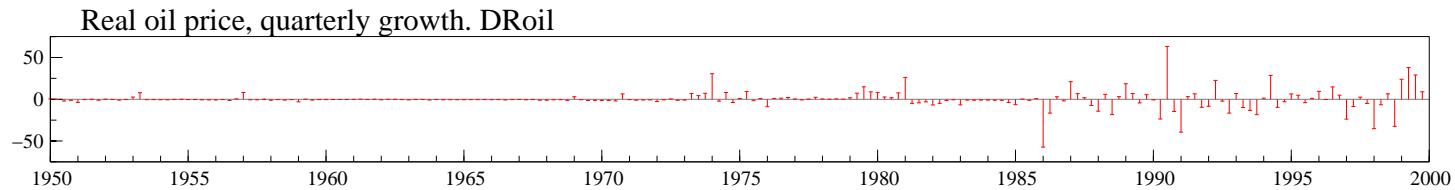

Net real increase compared to previous year. NOPI
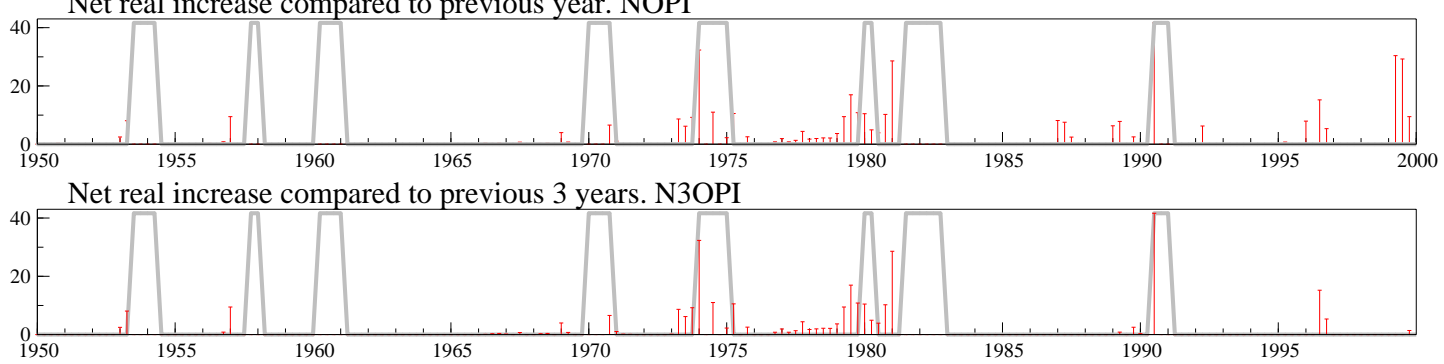

Lee, Ni and Ratti series. LNR

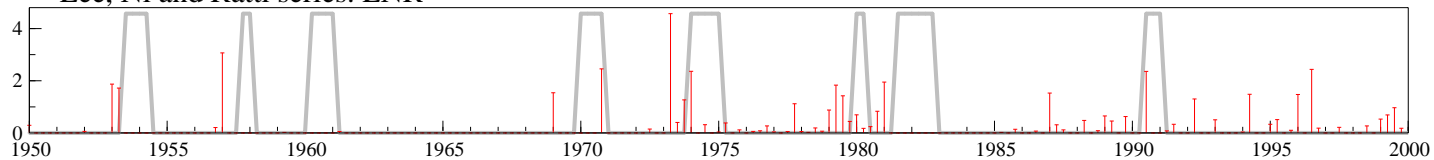

Exogenous oil supply disruptions, Quant.

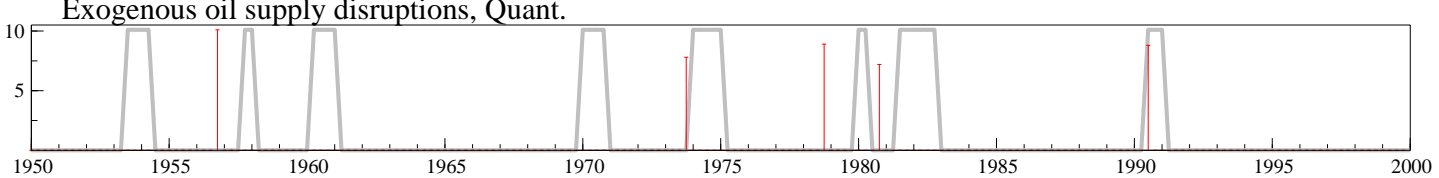

Figure 1 Oil price transforms. The panels show the quarterly growth rate in the real oil (DRoil) where the deflator is the GDP deflator, Hamilton's net real oil price variable (NOPI), Hamilton's net real oil price variable relative to the previous three years (N3OPI), the Lee, Ni and Ratti (LNR) variable, and a time series of exogenous supply disruptions (Quant). Overimposed are the NBER recessions..

The outcome of this exercise suggests using the LNR transformation of the oil price in the MS-AR model of output growth, but because the ADL model findings are at best indicative - we cannot show that the transformation that offers the best linear fit is the most appropriate in the MS-AR framework we also check the asymmetry results for oil price variables.

\subsection{Two-regime models of the US Business Cycle}

Within the class of Markov-Switching autoregressive models, there are a large variety of models that could be used to investigate the role of oil prices. As well as combinations of the number of regimes and lag order $\{M, p\}$, there is the choice of switching means versus intercepts (only equivalent for $p=0$ ), switching autoregressive parameters, and regime-dependent error variances (see e.g., Krolzig, 1997). We use the simplest models that are capable of capturing the features of interest of the business cycle as our benchmark univariate models, which include the ability to reproduce the NBER recession timings. Formal model selection procedures are made difficult and unreliable by the well-documented problems that affect inference in choosing between some of the variants. The relatively small number of cycles in the post War period suggest to us that complicated models with switching autoregressive parameters may be asking too much of the data, and in fact even the simplest models are capable of generating fairly complex behavior, suggesting that erring on the side of parsimony may be without much cost. Raymond and Rich (1997) appear to have followed this strategy: they set $M=2$ and $p=0$ in (1) (Hamilton, 1989, had $p=4)$,

$$
x_{t}=\mu\left(s_{t}\right)+\epsilon_{t}, \quad \epsilon_{t} \sim \operatorname{NID}\left(0, \sigma^{2}\right),
$$



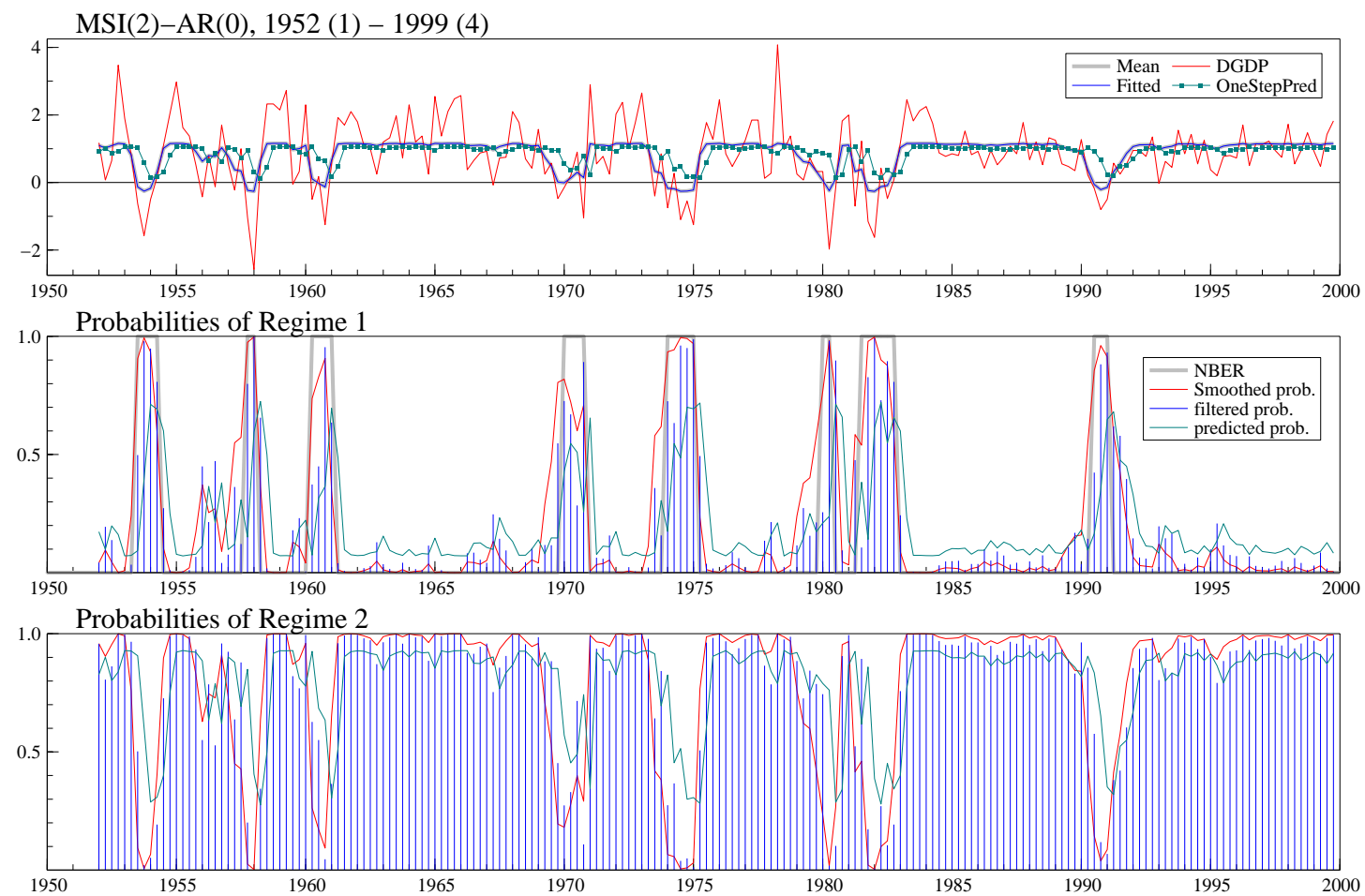

Figure $2 \mathrm{MS}(2)-\mathrm{AR}(0)$ model of US output growth. The top panel the sold line is the actual series, the pointed line is the one-step prediction, the dashed line is the fit of the model, and the bold gray line represents the contribution of the Markov chain. In the lower two panels, the bares gives the filtered probabilities, dashed line the one-step predicted probabilities, and the solid line the smoothed probabilities, of the 'contraction' and 'expansion' regimes, respectively. .

and we begin by estimating this model for the period $1952-1999$.

Figure 2 shows that such a model is able to capture the NBER recessions. The second and third panels depict the probabilities of being in the contraction and expansion regimes, respectively, where the mean growths are estimated to be -0.27 and 1.16 percent per quarter, and the expected durations of expansions and contractions are 14 and 4 quarters. The filtered regime probabilities are shown with a bar, the one-step predicted probabilities with a dashed line and the smooth probabilities are shown with a bold line. The filtered probability can be understood as an optimal inference on the state variable (whether the system is in a boom or recession) at time $t$ using only the information up to time $t$, i.e. $\operatorname{Pr}\left(s_{t}=m \mid Y_{t}\right)$, where $m$ stands for a given regime. The smoothed probability stands for the optimal inference on the regime at time $t$ using the full sample information, $\operatorname{Pr}\left(s_{t}=m \mid Y_{T}\right)$. In general the differences between the two are small and unimportant. In the second panel of figure 2 we overimposed the NBER Business Cycle to the inferred probability of a recession by the MS-AR. Comparing these figures confirms the ability of Hamilton's basic model to capture the phases of expansion and contraction over this period.

The non-parametric (NP) tests are recorded in table 1. On the basis of the NP tests of steepness and deepness there are no signs of asymmetries in the US output growth, $\Delta y_{t}$, over this period. In contrast the NP tests show evidence for deepness and steepness in employment growth, $\Delta n_{t}$, and we will discuss MS models involving employment in section 3.4.

The tests for SDS for the MSM(2)-AR(0) model are recorded in table 2. Below the table we note the NBER Business Cycle reference dates. Although the NP tests do not indicated asymmetries, our tests depict sharpness (because $p_{12}>p_{21}$ ) at the $1.1 \%$ level, and deepness of recessions, at the $2.3 \%$ level. 
Table 1 Non-parametric evidence for asymmetries in US output and employment growth.

\begin{tabular}{|c|c|c|c|}
\hline & & $\Delta y_{t}$ & $\Delta n_{t}$ \\
\hline Test & asymmetry & sign statistic $p$-value & sign statistic $p$-value \\
\hline \multicolumn{4}{|c|}{ Sample: $1960: 1-1999: 4$} \\
\hline Skewness of $x$ & Deepness & $2.0732[0.1499]$ & $31.2678[0.0000]^{* *}$ \\
\hline Skewness of $\Delta x$ & Steepness & $1.2099[0.2714]$ & $9.0880[0.0026]^{* *}$ \\
\hline \multicolumn{4}{|c|}{ Sample: $1952: 1-1999: 4$} \\
\hline Skewness of $x$ & Deepness & $3.9163[0.0478]^{*}$ & $29.4400[0.0000]^{* *}$ \\
\hline Skewness of $\Delta x$ & Steepness & $1.1695[0.2795]$ & $+16.4541[0.0000]^{* *}$ \\
\hline
\end{tabular}

Next, we estimate the MSM(2)-AR(0) model allowing for four lagged values of the LNR oil price variable. It is apparent from figure 3 that the shifts between states no longer correspond to the expansionary and contractionary phases of the business cycle: in fact $39 \%$ of observations are in the lower regime growth and the mean growth rate is positive in both states. The expected duration of the lower regime is around 3.3 quarters, and of the upper 5.2. It is inappropriate to test for asymmetries within such a model, because the results would not bear on the business cycle phases of expansion and contraction.
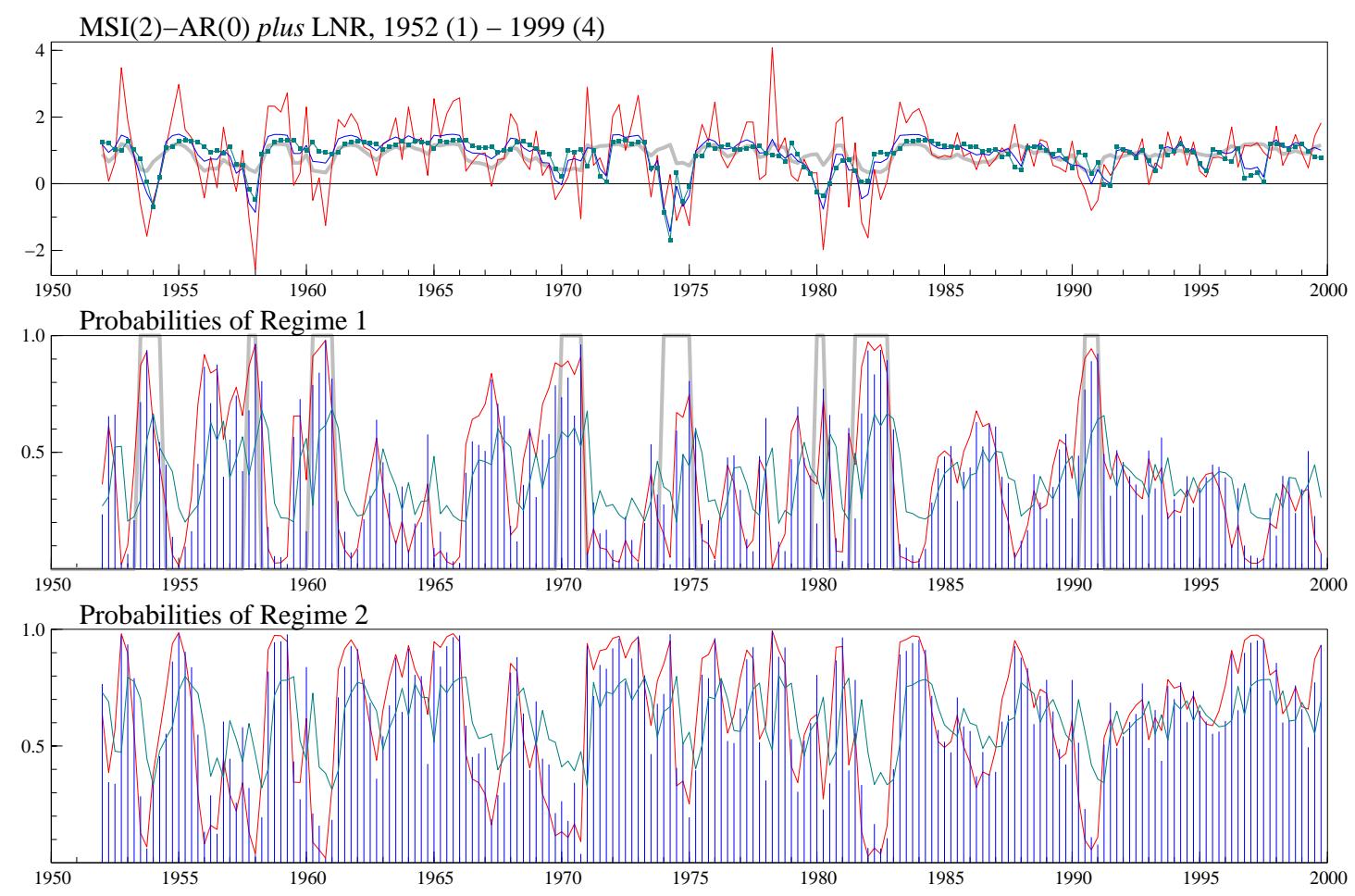

Figure $3 \mathrm{MSM}(2)-\mathrm{AR}(0)$ model of US output growth with lags 1-4 of the LNR oil price variable .

In table 2 the outcomes of the sharpness and deepness test are reported for MS(2) models with oil price shock measures. The most striking fact is that for all six models the tests indicate the deepness of recessions (positive skewness of $\Delta y_{t}$ ). But only the models with DRoil and Quant show indications of business cycle asymmetries. The failure of the models to detect any business cycle asymmetries might be due to the lagged oil price variables largely mopping up the asymmetries in the output series. ${ }^{2}$

\footnotetext{
${ }^{2}$ Clements and Smith (2000) find that the non-linear terms in the Pesaran and Potter (1997) 'ceiling and floor' model of US output growth become less important when lagged unemployment rate terms are added to the model; a similar phenomenon to that alluded to here.
} 
Table 2 Tests for asymmetries in MSI(2)-ADL(0,4) models of US output growth, 1952:1 - 1999:4.

\begin{tabular}{|c|c|c|c|c|c|c|}
\hline & MS-AR & MS-AR plus DRoil & MS-AR plus LNR & MS-AR plus N1DRoil & MS-AR plus N3DRoil & MS-AR plus Quant \\
\hline Test & sign statistic $p$-value & sign statistic $p$-value & sign statistic $p$-value & sign statistic $p$-value & sign statistic $p$-value & sign statistic $p$-value \\
\hline NonSharpness & $6.4071[0.0114]^{*}$ & $5.7847[0.0162]^{*}$ & $0.1163[0.7331]$ & $0.054[0.8162]$ & $0.8441[0.3582]$ & $8.2692[0.0040]^{* *}$ \\
\hline NonDeepness & $5.1413[0.0234]^{*}$ & $3.3721[0.0663]^{+}$ & $0.1520[0.6966]$ & $0.064[0.7996]$ & $0.5697[0.4504]$ & $3.6533[0.0560]^{+}$ \\
\hline \multicolumn{7}{|l|}{ Ergodic prob. } \\
\hline $\operatorname{Pr}\left(s_{1}=1\right)$ & 0.2054 & 0.2118 & 0.3870 & 0.3374 & 0.1560 & 0.1349 \\
\hline $\operatorname{Pr}\left(s_{1}=2\right)$ & 0.7946 & 0.7882 & 0.6130 & 0.6626 & 0.8440 & 0.8651 \\
\hline \multicolumn{7}{|l|}{ Synchronization } \\
\hline NBER & 0.8984 & 0.8924 & 0.6906 & 0.7522 & 0.8475 & 0.9047 \\
\hline $\operatorname{Pr}\left(s_{1}=1 \mid\right.$ rec. $)$ & 0.8422 & 0.8431 & 0.7613 & 0.7971 & 0.5194 & 0.6326 \\
\hline $\operatorname{Pr}\left(s_{1}=1 \mid\right.$ exp. $)$ & 0.0912 & 0.0985 & 0.3225 & 0.2561 & 0.0917 & 0.0449 \\
\hline AIC & 2.7952 & 2.8196 & 2.6753 & 2.7671 & 2.7495 & 2.7862 \\
\hline
\end{tabular}

The SD test statistics are $\chi^{2}$ with one degree of freedom under the null of symmetry.

** indicates significance at the $1 \%$ levelp

* indicates significance at the $5 \%$ level;

$+\quad$ indicates significance at the $10 \%$ level.

A '+' ('-') in the columns headed 'Sign' indicates positive (negative) skewness.

Note: Non-steepness is a property of the 2-regime model.

'Synchronization' reports the frequency that the NBER dated cycle and the Markov chain are in the same state of recession or expansion. 'Pr $\left(s_{1}=1 \mid\right.$ NBER recession) ' denotes the synchronization of MS and NBER recessions. It is measured as the average smoothed probability of beeing in regime 1 of the estimated MS-model when the US economy is in a recession according to the NBER. Similarily ' $\operatorname{Pr}\left(s_{1}=1 \mid\right.$ NBER expansion) ' reports the probability of a recession infered from the MS-VAR when the US economy is in state of an expansion according to the NBER.

The NBER turning points over this period are 54:2(T), 57:3(P), 58:2(T), 60:2(P), 61:1(T), 69:4(P), 70:4(T), 73:4(P), 75:1(T), 80:1(P), 80:3(T), 81:3(P), 82:4(T), 90:3(P), 91:1(T), where T \& P denote trough and peak, respectively 
But it is still premature to argue that oil prices account for the recurrent business cycle shifts between expansion and contraction: rather the addition of LNR variable serves to highlight the fragility of the two-state model noted by, e.g., Hess and Iwata (1997), Boldin (1996) and Clements and Krolzig (1998).

\subsection{Asymmetry in three-regime models of the US Business Cycle}

Sichel (1994) has argued convincingly that post-War business cycles typically consist of three phases: contraction, followed by high-growth recovery, and then a period of moderate growth. Clements and Krolzig (1998) capture this in a parametric model via a three-state heteroscedastic model with a switching intercept:

$$
x_{t}=\mu\left(s_{t}\right)+\sum_{k=1}^{4} \alpha_{k} x_{t-k}+\epsilon_{t},
$$

where $\epsilon_{t} \sim \operatorname{NID}\left(0, \sigma^{2}\left(s_{t}\right)\right)$ and $s_{t} \in\{1,2,3\}$ is generated by a Markov chain.

When we do so in the absence of the oil price variable we obtain the characterization of the business cycle given in figure 4. Panel 2 indicates that the dating of the recessionary periods are very close to those given by the two-regime model and the NBER chronology. The trend growth rate in the lower regime is -0.05 , in the middle regime 0.9 , and in the upper regime $1.35 \%$. The forth panel indicates that the rapid growth regime invariably follows the recession regime, as described by Sichel (1994). The assumption of homogeneous error variances across regimes is clearly rejected in such a model, based on a standard likelihood ratio test (which is asymptotically $\chi^{2}$ with $M-1$ degrees of freedom, conditional upon the number of regimes being the same in both models).
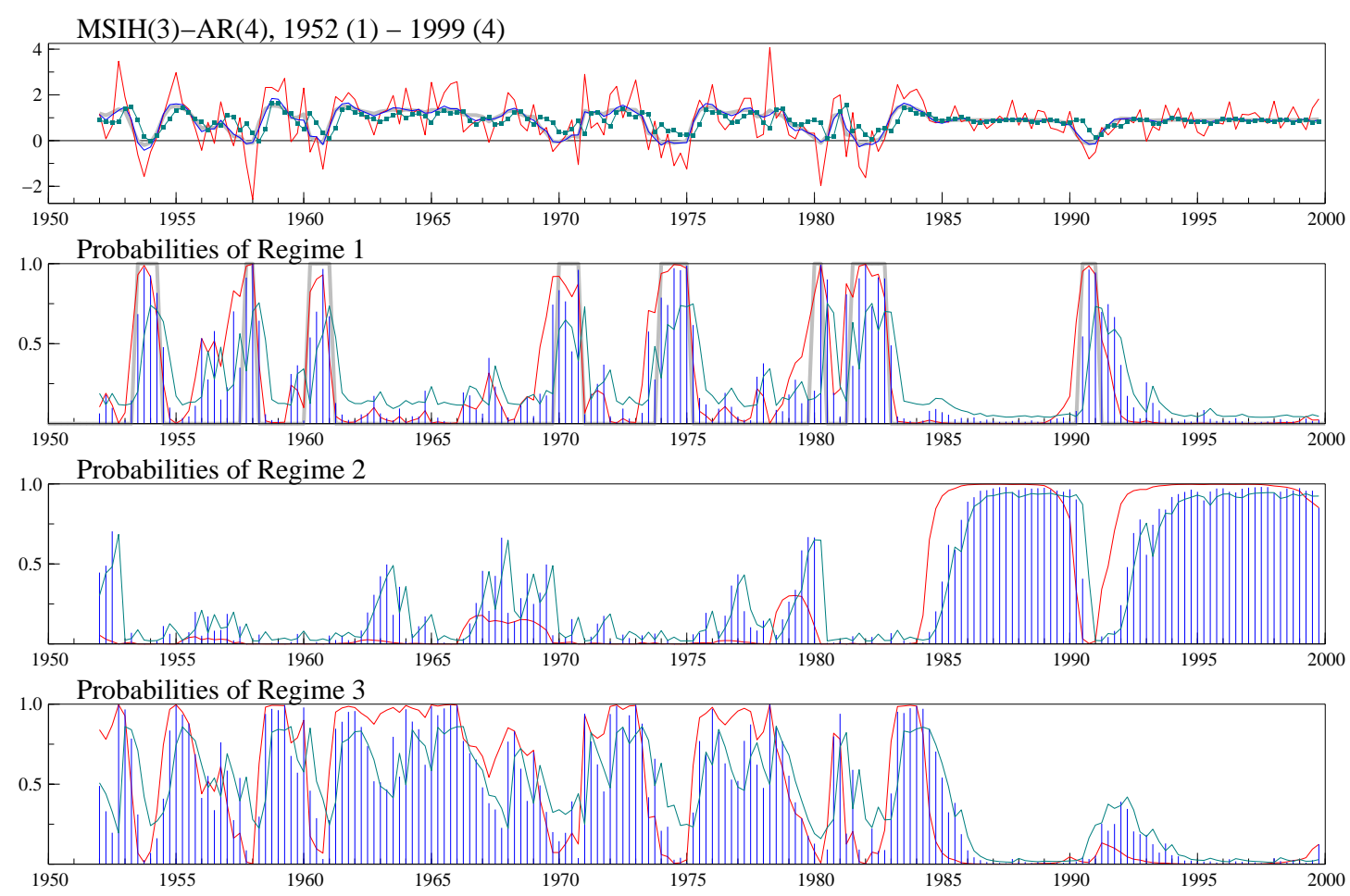

Figure 4 MSIH(3)-AR(4) model of US output growth.

Suppose the US business cycle is best described by the three-regime process. When the number of regimes is restricted to two, the model fails to capture the rapid growth periods, but picks up the recession periods and normal growth (expansion) periods. The inclusion of the oil variable accounts for enough 

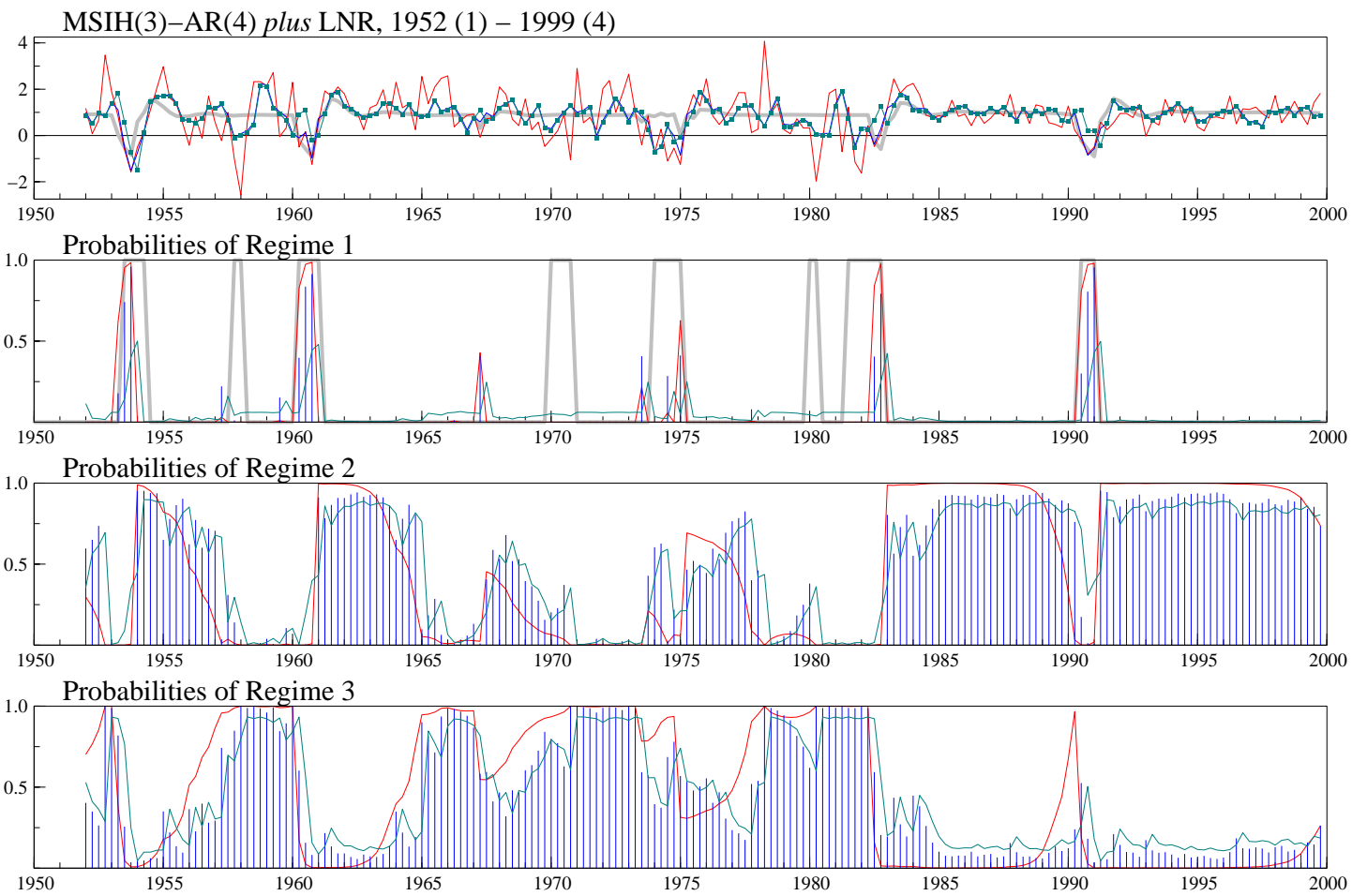

Figure 5 MSIH(3)-AR(4) model of US output growth with lags 1-4 of the LNR oil price variable .

of the dips in output for the optimization routine to cause the regimes to flip so that normal growth and rapid growth are matched. The three-regime model is more robust in that a regime is assigned to each of the three distinct phases: see figure 5. Though the inclusion of oil does affect the while it very precisely detects the NBER recessions in 1953, 1960. 1982 and 1990 it misses the recessions in 1957/58, 1970 and 1980. Inspection of figure 1 reveals that the 'non-detected' recessions are preceded by peaks in LNR. This should not be interpreted as a failure of the MS model: as the 'non-detected' recessions have been can be 'explained' by LNR, regime one collects only those recessions which are not associated by oil price shocks.

Table 3 records that all three-regime model tend to indicate steepness of expansions and deepness of recessions, whether oil is included or not. While the signs of skewness implied by the MSIH(3)ADLs confirm the findings of the two-state models, the statistical evidence is much weaker. For the MSIH(3)-AR(4) model, non-deepness cannot be rejected and the steepness of expansions is marginally insignificant at the $10 \%$ level. For the MS-AR plus LNR, non-sharpness $\left(p_{12}=p_{32}\right)$ and non-deepness can be rejected at the 5\% and $1 \%$ level, respectively. The MS-AR is steep at $10 \%$ when DRoil is included and at 5\% in case of N1DRoil. All MS models including oil price transforms show reasonable business cycle features, though in the case of N3DRoil and Quant the second regime is absorbing signaling the current obsoleteness of the business cycle. The finding of steepness in the three-regime models appears quite robust to whether we allow for heteroscedastic errors in the MS-AR model (see Clements and Krolzig, 2000, for a discussion of the effects of heteroscedastic errors on tests for asymmetry) and on which of the five oil price variables is used. For example, using the homoscedastic three-regime model with either the NOPI, N3OPI, Quant or LNR variables, we found steepness of expansions at the $1 \%$ level (and at the 10\% level for the DRoil variables).

Univariate Markov-switching models are only able to capture some of the stylized facts of the business cycle as they do not reflect the idea of comovement among economic time series which is essential 
Table 3 Tests for asymmetries in MSIH(3)-ADL(4,4) models of US output growth, 1952:1 - 1999:4.

\begin{tabular}{|c|c|c|c|c|c|c|}
\hline & MS-AR & MS-AR plus DRoil & MS-AR plus LNR & MS-AR plus N1DRoil & MS-AR plus N3DRoil & MS-AR plus Quant \\
\hline Test & sign statistic $p$-value & sign statistic $p$-value & sign statistic $p$-value & sign statistic $p$-value & sign statistic $p$-value & sign statistic $p$-value \\
\hline NonSharpness & $1.2424[0.7429]$ & $1.1810[0.7576]$ & $4.6961[0.1954]$ & $1.3197[0.7245]$ & $0.7931[0.8511]$ & $3025.3[0.0000]^{* *}$ \\
\hline$p_{12}=p_{32}$ & $0.0124[0.9112]$ & $0.0119[0.9131]$ & $4.4610[0.0347]^{*}$ & $0.0127[0.9104]$ & $0.0378[0.8458]$ & $1673.7[0.0000]^{* *}$ \\
\hline$p_{13}=p_{31}$ & $1.1810[0.2772]$ & $1.1738[0.2786]$ & $0.2658[0.6062]$ & $1.3068[0.2530]$ & $0.3796[0.5378]$ & $1.3055[0.2532]$ \\
\hline$p_{21}=p_{23}$ & $0.0141[0.9056]$ & $0.0477[0.8270]$ & $0.0111[0.9162]$ & 0.0519 [0.8197] & $0.3743[0.5407]$ & $0.0111[0.9163]$ \\
\hline NonDeepness & $0.4433[0.5055]$ & $0.5109[0.4747]$ & $-\quad 40.0960[0.0000]^{* *}$ & $0.5632[0.4530]$ & $0.0189[0.8906]$ & $0.0703[0.7909]$ \\
\hline NonSteepness & $2.6289[0.1049]$ & $3.5325[0.0602]^{+}$ & $0.6998[0.4028]$ & $4.2426[0.0394]^{*}$ & $0.6170[0.4322]$ & $0.8409[0.3591]$ \\
\hline \multicolumn{7}{|l|}{ Ergodic prob. } \\
\hline $\operatorname{Pr}\left(s_{1}=1\right)$ & 0.2315 & 0.2219 & 0.0566 & 0.2228 & 0.0000 & 0.0000 \\
\hline $\operatorname{Pr}\left(s_{1}=2\right)$ & 0.3766 & 0.4042 & 0.4992 & 0.4118 & 1.0000 & 1.0000 \\
\hline $\operatorname{Pr}\left(s_{1}=3\right)$ & 0.3920 & 0.3739 & 0.4443 & 0.3653 & 0.0000 & 0.0000 \\
\hline \multicolumn{7}{|l|}{ Synchronization } \\
\hline NBER & 0.8740 & 0.8723 & 0.8889 & 0.8773 & 0.8416 & 0.8622 \\
\hline $\operatorname{Pr}\left(s_{1}=1 \mid\right.$ rec. $)$ & 0.8983 & 0.8973 & 0.3331 & 0.9244 & 0.5444 & 0.6755 \\
\hline $\operatorname{Pr}\left(s_{1}=1 \mid\right.$ exp. $)$ & 0.1305 & 0.1323 & 0.0082 & 0.1314 & 0.1034 & 0.1033 \\
\hline AIC & 2.7153 & 2.7169 & 2.5945 & 2.7004 & 2.6441 & 2.6411 \\
\hline
\end{tabular}

Under the null of symmetry, the SDS test statistics are $\chi^{2}$ with one degree of freedom; the NonSharpness has three degrees of freedom.

** indicates significance at the $1 \%$ level;

* indicates significance at the $5 \%$ level;

+ indicates significance at the $10 \%$ level.

A '+' ('-') in the columns headed 'Sign' indicates positive (negative) skewness.

'Synchronization' reports the frequency that the NBER dated cycle and the Markov chain are in the same state of recession or expansion. 'Pr $\left(s_{1}=1 \mid\right.$ NBER recession) ' denotes the synchronization of MS and NBER recessions. It is measured as the average smoothed probability of beeing in regime 1 of the estimated MS-model when the US economy is in a recession according to the NBER. Similarily ' $\operatorname{Pr}\left(s_{1}=1 \mid\right.$ NBER expansion) ' reports the probability of a recession infered from the MS-VAR when the US economy is in state of an expansion according to the NBER. 
to the notion of a business cycle. In the following we generalize the MS-AR models considered so far to a cointegrated Markov-switching vector autoregressive model (MS-VAR) of US output and employment. If the business cycle is a common feature of many macroeconomic time series, modeling the system improves the statistical inference of the Markov process in extracting the common 'business cycle' component from the group of economic time series. Hopefully this will sharpen our judgment of the effects of oil price shocks on the asymmetry of the business cycle.

\subsection{Oil price shocks in a model of US output and employment}

The Krolzig and Toro (1998) model of post-war US employment and output data is a cointegrated vector autoregressive Markov-switching process, where some parameters are changing according to the phase of the business and employment cycle. Employment and output are found to have a common cyclical component, and the long run dynamics are characterized by a proportional cointegrating vector between employment and output, with a trend $(t)$ included as a proxy for technological progress and capital accumulation.

More formally, the long-run relationship between (the logs of) output, $y_{t}$, and employment, $n_{t}$, is given by the cointegration vector $\beta^{\prime}=(1:-1)$ and the regime-dependent deviation from the trend in per-capita output $\mu\left(s_{t}\right)=\mathrm{E}\left[y_{t-1}-n_{t-1}-\gamma(t-1)\right]$. Then each regime $m$ is associated with a particular attractor $\left(\mu_{m}, \delta_{m}^{*}\right)$ given by the equilibrium growth rate $\delta_{m}^{*}$ and the equilibrium mean $\mu_{m}$ :

$$
\left[\begin{array}{ll}
a_{11}(\mathrm{~L}) & a_{12}(\mathrm{~L}) \\
a_{21}(\mathrm{~L}) & a_{22}(\mathrm{~L})
\end{array}\right]\left[\begin{array}{c}
\Delta y_{t}-\delta^{*}\left(s_{t}\right) \\
\Delta n_{t}-\delta^{*}\left(s_{t}\right)
\end{array}\right]=\left[\begin{array}{l}
\alpha_{1} \\
\alpha_{2}
\end{array}\right]\left(y_{t-1}-n_{t-1}-\gamma(t-1)-\mu\left(s_{t}\right)\right)+\left[\begin{array}{l}
u_{1 t} \\
u_{2 t}
\end{array}\right],
$$

where $u_{t} \mid s_{t} \sim \operatorname{NID}\left(\mathbf{0}, \Sigma\left(s_{t}\right)\right)$. Thus the regime-dependent drift term $\delta^{*}\left(s_{t}\right)$ is the equilibrium growth rate, and shifts in the $\delta^{*}\left(s_{t}\right)$ map out changes in the business cycle state (e.g., expansion, contraction). The equilibrium mean $\mu\left(s_{t}\right)$ gives the state-dependent equilibrium level of labour productivity: shifts in $\mu\left(s_{t}\right)$ reflect changes in equilibrium per-capita output. As in the univariate MS models, the unobservable regime variable $s_{t}$ is governed by a Markov chain with a finite number of states defined by the transition probabilities $p_{i j}$.

The maximum likelihood (ML) estimation of the model using data from 1960:1 to 1999:4 is based on a version of the Expectation-Maximization (EM) algorithm discussed in Hamilton (1990) and Krolzig (1997), and follows the two-stage procedure suggested by Krolzig (1996). The cointegration properties of the system are analyzed within a linear VAR(4) representation using the ML method of Johansen (1995): The trace test supports cointegration rank one and the cointegrating vector is identified as trendadjusted productivity:

$$
y n_{t}=y_{t}-n_{t}-0.244 t
$$

which is interpreted by Krolzig and Toro (1998) as a labour-based measurement of capacity utilization. Productivity grew at an average rate of about $2.4 \%$ per year and deviations from this trend are stationary. Short-run and long-run dynamics are jointly estimated in a Markov-switching vector-equilibriumcorrection (MS-VECM) model with three regimes representing recession, growth and high growth. The ML estimation results for a first-order model estimated are presented in table 4 , for the model parameterized as:

$$
\left[\begin{array}{l}
\Delta y_{t} \\
\Delta n_{t}
\end{array}\right]=\left[\begin{array}{l}
\nu_{1}\left(s_{t}\right) \\
\nu_{2}\left(s_{t}\right)
\end{array}\right]+\left[\begin{array}{ll}
a_{11} & a_{12} \\
a_{21} & a_{22}
\end{array}\right]\left[\begin{array}{c}
\Delta y_{t-1} \\
\Delta n_{t-1}
\end{array}\right]+\left[\begin{array}{l}
\alpha_{1} \\
\alpha_{2}
\end{array}\right] y n_{t-1}+\left[\begin{array}{l}
u_{1 t} \\
u_{2 t}
\end{array}\right],
$$

with $\nu\left(s_{t}\right)=\delta\left(s_{t}\right)-\alpha \mu\left(s_{t}\right)$. 
Table 4 ML Estimation Results for the MSIH(3)-VECM(4) Model, 1960:1 - 1999:4.

\begin{tabular}{|c|c|c|c|c|}
\hline & \multicolumn{2}{|c|}{ 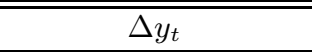 } & \multicolumn{2}{|c|}{ 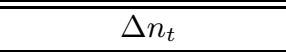 } \\
\hline \multicolumn{5}{|c|}{ Regime-dependent intercepts } \\
\hline$\nu_{1}$ & -0.4297 & $(0.2025)$ & -0.2244 & $(0.0906)$ \\
\hline$\nu_{2}$ & 0.7692 & $(0.1139)$ & 0.2473 & $(0.0436)$ \\
\hline$\nu_{3}$ & 1.3161 & $(0.1946)$ & 0.4348 & $(0.0718)$ \\
\hline \multicolumn{5}{|c|}{ Short-run dynamics } \\
\hline$\Delta y_{t-1}$ & -0.0512 & $(0.0924)$ & 0.0030 & $(0.0327)$ \\
\hline$\Delta n_{t-1}$ & 0.2279 & $(0.1636)$ & 0.5679 & $(0.0584)$ \\
\hline \multicolumn{5}{|c|}{ Equilibrium correction } \\
\hline$y n_{t-1}$ & -2.5337 & (4.1919) & 3.0889 & $(1.4884)$ \\
\hline \multicolumn{5}{|c|}{ Standard Errors } \\
\hline Regime 1 & 0.7834 & & 0.3408 & \\
\hline Regime 2 & 0.4592 & & 0.1362 & \\
\hline Regime 3 & 0.7855 & & 0.3086 & \\
\hline \multicolumn{5}{|c|}{ Correlation } \\
\hline Regime 1 & 0.6165 & & & \\
\hline Regime 2 & 0.3572 & & & \\
\hline Regime 3 & 0.6128 & & & \\
\hline Fitting & MS-VECM & & linear VECI & \\
\hline logLik & -141.5922 & & -183.2934 & \\
\hline AIC & 2.1207 & & 2.4439 & \\
\hline HQ & 2.3323 & & 2.5302 & \\
\hline SC & 2.6418 & & 2.6563 & \\
\hline$p_{i j}$ & $s_{t-1}=1$ & $s_{t-1}=2$ & $s_{t-1}=3$ & Duration \\
\hline$s_{t}=1$ & 0.7713 & 0.0449 & 0.0412 & 4.37 \\
\hline$s_{t}=2$ & 0.0256 & 0.9551 & 0.0608 & 22.27 \\
\hline$s_{t}=3$ & 0.2030 & .000003 & 0.8981 & 9.81 \\
\hline
\end{tabular}

Notes: The numbers in brackets represent the standard errors of the estimated coefficients. MSIH-VECM denotes the estimated VECM with regime shifts in the (I)ntercept and regime-dependent (H)eteroskedasticity. 

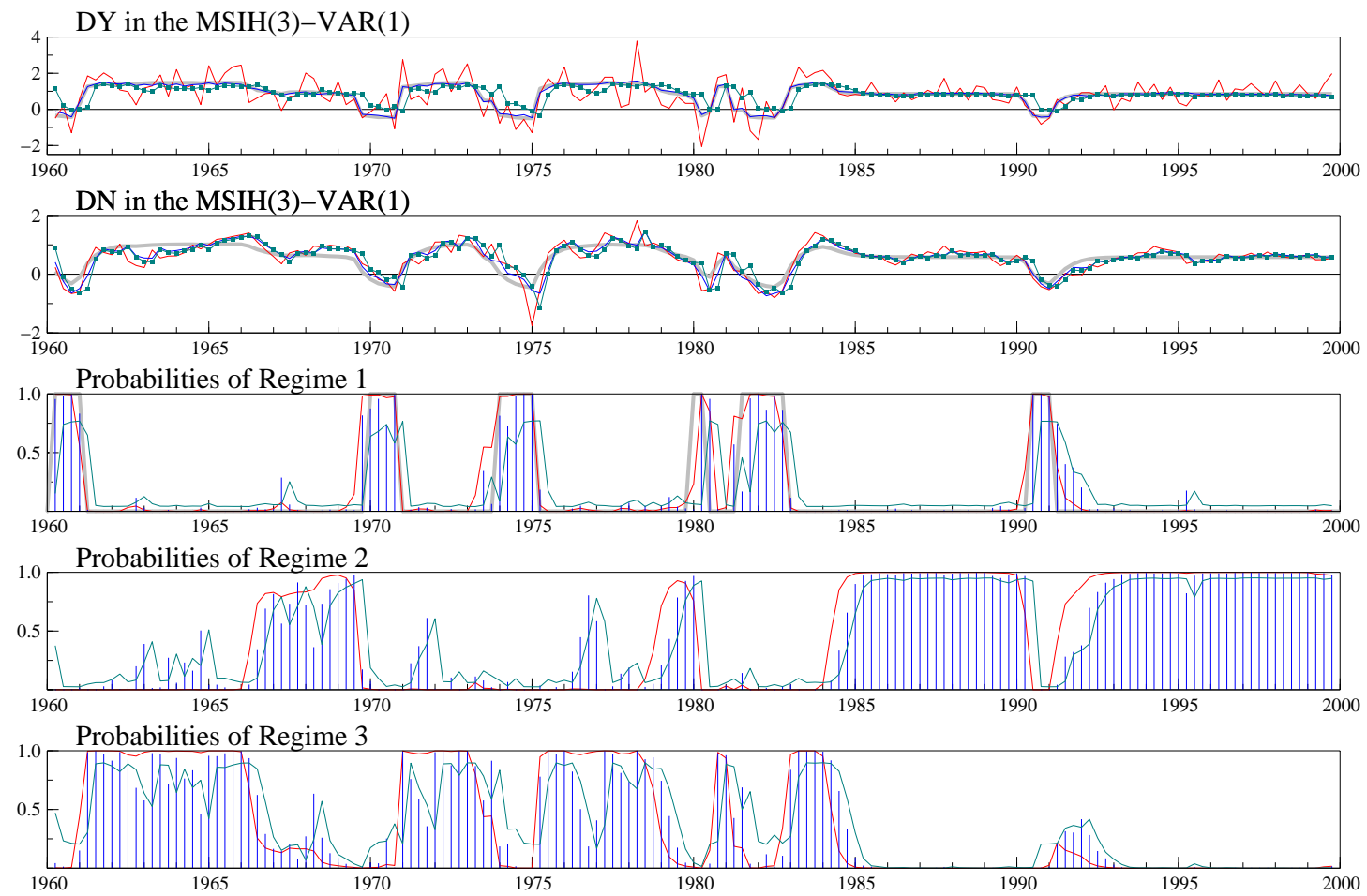

Figure 6 The US Business Cycle in output and employment.

The resulting regime probabilities are plotted in the lower three panels of figure 6. As in the univariate case, the smoothed probabilities assign each observation to a particular state using all the sample information; the filtered use information available only up to that observation. The findings confirm the conventional wisdom of a business cycle which can be separated in three stages: recession, growth, and high growth. It can be seen that regime 1 depicts very precisely the NBER recessions of 1970, 1973/74, 1979/80 and 1990. Regime 2 represents normal growth episodes; while regime 3 characterizes high-growth episodes mainly occurring after recessions. Note that regime 3 is observed until 1985 only, which might indicate a structural change in the phase structure of the business cycle. Expansions after 1985 (regime 2) are characterized by a lower mean growth rate and reduced volatility of macroeconomic fluctuations. This structural break in the volatility of US output growth coincides with the findings of McConnell and Quiros (1998). They found a substantial reduction in the volatility of durable goods production beginning with the first quarter of 1984, which appears to be correlated with a decline in the share of durable goods accounted for by inventories. The upper two panels show how the inferred regime probabilities are translated into shifts in the mean growth rate of output and employment: Thus the bold gray line represents the contribution of the hidden Markov chain to the fluctuations in the variables of the system, the thin line gives the fit and the line with the points gives the one-step prediction.

Figure 7 shows the results when the MS-VECM of output and employment (9) is conditioned on the first four lags of LNR. When compared to the bivariate MS-VECM, the reconstructed recessions are shorter and more pronounced. Particularly the 1973/74 recession is traced back to the peaks in the LNR regressor and, hence, it is not recognized as classical recessions.

Test results for asymmetries in the models of the vector process are reported in table 5. The left column is the MS-VECM of Krolzig and Toro (1998). As in the tables reporting the univariate models, we compare the MSIH(3)-VECM(1) with conditional models involving the first four lags of the five oil price transforms. We find not only evidence of steepness in both output and employment growth but 
Table 5 Tests for asymmetries in MSIH(3)-VECM(1) models of US output and employment growth, 1960:1 - 1999:4.

\begin{tabular}{|c|c|c|c|c|c|c|}
\hline & MS-VECM & MS-VECM plus DRoil & MS-VECM plus LNR & MS-VECM plus N1DRoil & MS-VECM plus N3DRoil & MS-VECM plus Quant \\
\hline Test & sign statistic $p$-value & sign statistic $p$-value & sign statistic $p$-value & sign statistic $p$-value & sign statistic $p$-value & sign statistic $p$-value \\
\hline NonSharpness & $3.4984[0.3210]$ & $2.3609[0.5010]$ & $6.1185[0.1060]$ & $2.5155[0.4725]$ & $3.1720[0.3659]$ & $0.3340[0.9535]$ \\
\hline$p_{12}=p_{32}$ & $0.2471[0.6191]$ & $0.0710[0.7899]$ & $0.0033[0.9539]$ & $0.1563[0.6926]$ & $0.0993[0.7527]$ & $0.3195[0.5719]$ \\
\hline$p_{13}=p_{31}$ & $3.4747[0.0623]^{+}$ & $2.1939[0.1386]$ & $6.1078[0.0135]^{*}$ & $2.3434[0.1258]$ & $3.0620[0.0801]^{+}$ & $0.0135[0.9077]$ \\
\hline$p_{21}=p_{23}$ & $0.0100[0.9203]$ & $0.0026[0.9592]$ & $0.0085[0.9266]$ & 0.0007 [0.9789] & $0.0133[0.9082]$ & $0.0005[0.9813]$ \\
\hline NonDeepness $\left(\Delta y_{t}\right)$ & $1.5833[0.2083]$ & $2.0707[0.1502]$ & $3.4789[0.0622]^{+}$ & $2.4720[0.1159]$ & $2.1612[0.1415]$ & $3.2081[0.0733]^{+}$ \\
\hline NonSteepness $\left(\Delta y_{t}\right)$ & $5.4891[0.0191]^{*}$ & $4.7949[0.0285]^{*}$ & $4.3867[0.0362]^{*}$ & $6.0498[0.0139]^{*}$ & $5.4029[0.0201]^{*}$ & $6.4975[0.0108]^{*}$ \\
\hline NonDeepness $\left(\Delta n_{t}\right)$ & $1.5652[0.2109]$ & $1.2038[0.2726]$ & $4.2876[0.0384]^{*}$ & $1.3800[0.2401]$ & $2.5327[0.1115]$ & $3.1078[0.0779]^{+}$ \\
\hline NonSteepness $\left(\Delta n_{t}\right)$ & $4.3341[0.0374]^{*}$ & $3.1728[0.0749]^{+}$ & $4.1180[0.0424]^{*}$ & $4.0938[0.0430]^{*}$ & $4.6269[0.0315]^{*}$ & $5.8674[0.0154]^{*}$ \\
\hline \multicolumn{7}{|l|}{ Ergodic prob. } \\
\hline $\operatorname{Pr}\left(s_{1}=1\right)$ & 0.1598 & 0.1609 & 0.1329 & 0.1586 & 0.1304 & 0.1231 \\
\hline $\operatorname{Pr}\left(s_{1}=2\right)$ & 0.5219 & 0.5010 & 0.4966 & 0.5162 & 0.5217 & 0.5087 \\
\hline $\operatorname{Pr}\left(s_{1}=3\right)$ & 0.3183 & 0.3380 & 0.3704 & 0.3252 & 0.3478 & 0.3681 \\
\hline \multicolumn{7}{|l|}{ Synchronization } \\
\hline NBER & 0.9513 & 0.9420 & 0.9536 & 0.9435 & 0.9588 & 0.9419 \\
\hline $\operatorname{Pr}\left(s_{1}=1 \mid\right.$ rec. $)$ & 0.9186 & 0.9627 & 0.8249 & 0.9793 & 0.8317 & 0.7337 \\
\hline $\operatorname{Pr}\left(s_{1}=1 \mid\right.$ exp. $)$ & 0.0429 & 0.0617 & 0.0235 & 0.0628 & 0.0186 & 0.0211 \\
\hline AIC & 2.1207 & 2.1782 & 2.1589 & 2.1746 & 2.1539 & 2.1166 \\
\hline
\end{tabular}

Under the null of symmetry, the SDS test statistics are $\chi^{2}$ with one degree of freedom; the NonSharpness has three degrees of freedom.

** indicates significance at the $1 \%$ level;

* indicates significance at the $5 \%$ level;

$+\quad$ indicates significance at the $10 \%$ level.

A ' + ' ('-') in the columns headed 'Sign' indicates positive (negative) skewness.

'Synchronization' reports the frequency that the NBER dated cycle and the Markov chain are in the same state of recession or expansion. 'Pr $\left(s_{1}=1 \mid\right.$ NBER recession) ' denotes the synchronization of MS and NBER recessions. It is measured as the average smoothed probability of beeing in regime 1 of the estimated MS-model when the US economy is in a recession according to the NBER. Similarily ' $\operatorname{Pr}\left(s_{1}=1 \mid\right.$ NBER expansion) ' reports the probability of a recession infered from the MS-VAR when the US economy is in state of an expansion according to the NBER. 

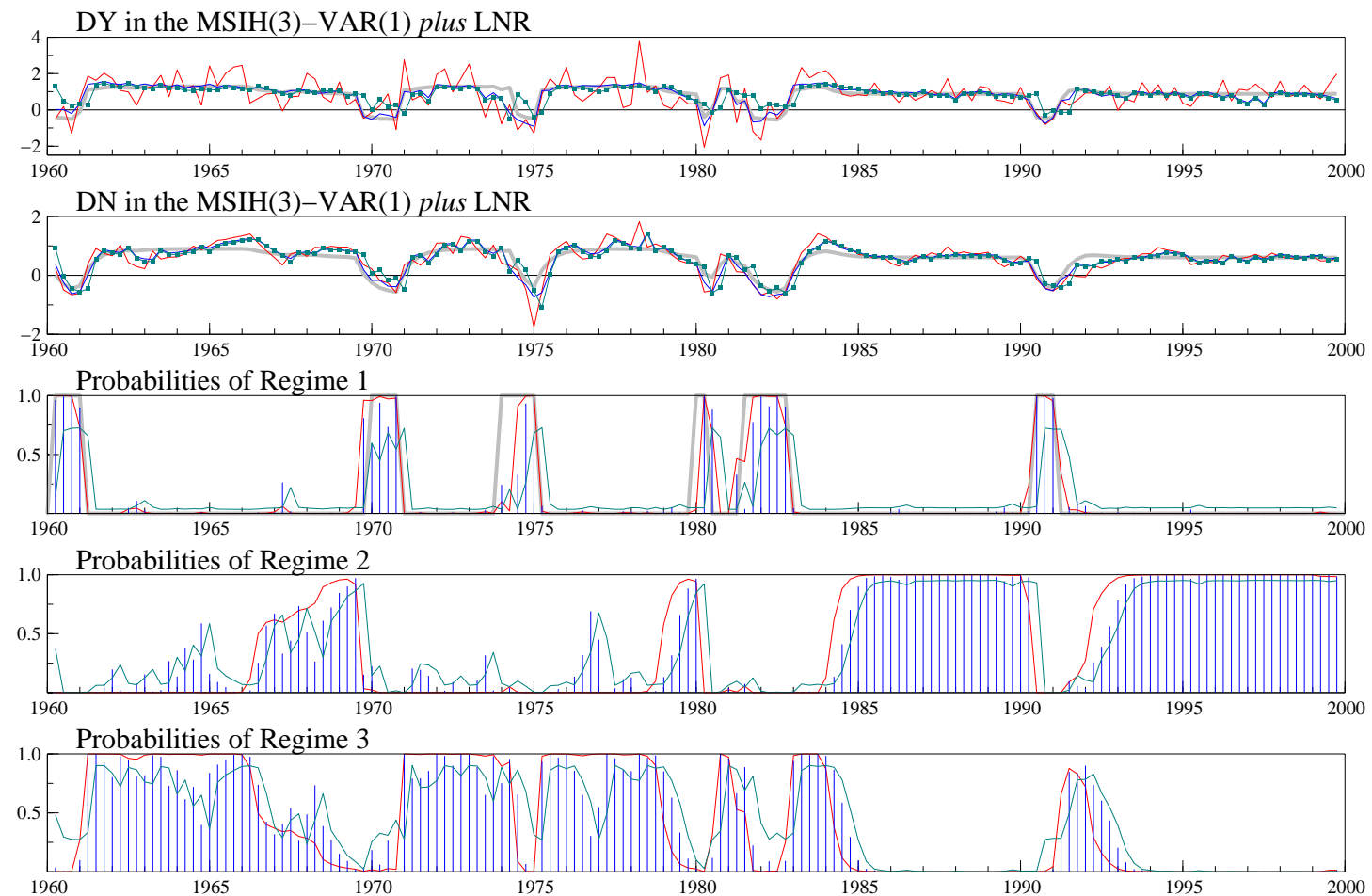

Figure 7 The US Business Cycle in output and employment when conditioned on LNR.

also sharpness. For all six models considered, the steepness of business cycles is confirmed at a 5\% significance level. For some of the models, there is also indication of sharpness due to $p_{31}<p_{13}$. When the MS-VECM is conditioned on LNR, recessions are found to be deep in output (at the 10\% level) and employment (at the $1 \%$ level).

A major advantage of the MS-VECM when compared to the MS-AR is that its regime classification is close to the NBER cycle dating with or without an oil variable: The synchronization of the MSVECM with the NBER benchmark is for all models greater than 0.94. Hence, it is justified to interpret the outcome of our SDS tests as measures for the effects of oil shocks on the asymmetry of the business cycle.

\section{Conclusions}

The relationship between oil and the macroeconomy has received much attention in the recent literature. In this paper we argued that a three-state Markov-Switching model that distinguishes between contractions, and divides expansions into 'normal' and rapid recovery growth, is the appropriate model in which to explore the explanatory power of oil prices for business cycle phases, especially recessions, and to investigate the role of oil in generating business cycle asymmetries. We tested the parameter restrictions that rule out SDS asymmetries, and could show that the outcomes are unaffected by allowing oil prices to affect the conditional mean of output growth. Our findings are broadly in line with those of Raymond and Rich (1997): oil prices do not appear to be the sole explanation of regime-switching behavior. Furthermore, the asymmetries detected in the business cycle do not appear to be explicable by oil prices.

While some of violence of economic downturns can be attributed to dramatic changes in the price of oil, the findings of the asymmetry tests consistently is that post-War US economic growth is charac- 
terized by steepness of expansions. Thus, whether with or without allowing for the effects of oil price shocks, the violence of business cycle transitions from the state of recession to an expansion is greater than when an expansion ends in a recession. The overwhelming evidence is strongly against the conventional wisdom (as in the definition of Burns and Mitchell) that recessions are more violent (i.e. steeper) than expansions.

\section{References}

Boldin, M. D. (1996). A check on the robustness of Hamilton's Markov switching model approach to the econometric analysis of the business cycle. Studies in Nonlinear Dynamics and Econometrics, $1,35-46$.

Clements, M. P., and Krolzig, H.-M. (1998). A comparison of the forecast performance of Markovswitching and threshold autoregressive models of US GNP. Econometrics Journal, 1, C47-75.

Clements, M. P., and Krolzig, H.-M. (2000). Business cycle asymmetries: Characterisation and testing based on Markov-switching autoregressions. mimeo, Department of Economics, University of Warwick.

Clements, M. P., and Smith, J. (2000). Evaluating the forecast densities of linear and non-linear models: Applications to output growth and unemployment. Journal of Forecasting, 19, 255-276.

Diebold, F. X., Rudebusch, G. D., and Sichel, D. E. (1993). Further evidence on business cycle duration dependence. In Stock, J., and Watson, M. (eds.), Business Cycles, Indicators, and Forecasting, pp. 255-280. Chicago: University of Chicago Press and NBER.

Doornik, J. A. (1999). Object-Oriented Matrix Programming using Ox 3rd edn. London: Timberlake Consultants Press.

Filardo, A. J. (1994). Business-cycle phases and their transitional dynamics. Journal of Business and Economic Statistics, 12, 299-308.

Filardo, A. J., and Gordon, S. F. (1998). Business cycle durations. Journal of Econometrics, 85, 99-123.

Hamilton, J. D. (1983). Oil and the Macroeconomy since World War II. Journal of Political Economy, 91, 228-248.

Hamilton, J. D. (1996). This is what happened to the oil price-macroeconomy relationship. Journal of Monetary Economics, 38, 215-220.

Hamilton, J. D. (2000). What is an Oil Shock. mimeo, Department of Economics, UCSD, La Jolla, California.

Hamilton, J. D. (1989). A new approach to the economic analysis of nonstationary time series and the business cycle. Econometrica, 57, 357-384.

Hamilton, J. D. (1990). Analysis of time series subject to changes in regime. Journal of Econometrics, 45, 39-70.

Hess, G. D., and Iwata, S. (1997). Measuring and comparing business-cycle features. Journal of Business and Economic Statistics, 15, 432-44.

Hooker, M. A. (1996). Whatever happened to the oil price-macroeconomy relationship?. Journal of Monetary Economics, 38, 195-213.

Johansen, S. (1995). Likelihood-Based Inference in Cointegrated Vector Autoregressive Models. Oxford: Oxford University Press. 
Krolzig, H.-M. (1996). Statistical analysis of cointegrated VAR processes with Markovian regime shifts. SFB 373 Discussion Paper 25/1996, Humboldt Universität zu Berlin.

Krolzig, H.-M. (1997). Markov Switching Vector Autoregressions. Modelling, Statistical Inference and Application to Business Cycle Analysis. Berlin: Springer.

Krolzig, H.-M. (1998). Econometric modelling of Markov-switching vector autoregressions using MSVAR for Ox. Discussion Paper, Department of Economics, University of Oxford: http://www.econ.ox.ac.uk/research/hendry/krolzig.

Krolzig, H.-M., and Hendry, D. F. (2000). Computer automation of general-to-specific model selection procedures. Forthcoming, Journal of Economic Dynamics and Control.

Krolzig, H.-M., and Toro, J. (1998). A new approach to the analysis of shocks and the cycle in a model of output and employment. Working paper eco 99/30, EUI, Florence.

Lee, K., Ni, S., and Ratti, A. (1995). Oil shocks and the macroeconomy: The role of price variability. Energy Journal, 16, 39-56.

Luukkonen, R., Saikkonen, P., and Teräsvirta, T. (1988). Testing linearity against smooth transition autoregressive models. Biometrika, 75, 491-499.

Luukkonen, R., and Teräsvirta, T. (1991). Testing linearity of economic time series against cyclical asymmetry. Annales d'économie et de statistique, 20/21, 125-142.

McConnell, M. M., and Quiros, G. P. (1998). Output fluctuations in the United States: what has changed since the early 1980s. Staff report no. 41, Federal Reserve Bank of New York.

McQueen, G., and Thorley, S. (1993). Asymmetric business cycle turning points. Journal of Monetary Economics, 31, 341-362.

Mitchell, W. C. (1927). Business Cycles: The Problem and its Setting. New York: National Bureau of Economic Research.

Mork, K. A. (1989). Oil and the Macroeconomy when prices go up and down: An extension of Hamilton's results. Journal of Political Economy, 97, 740-744.

Newey, W. K., and West, K. D. (1987). A simple positive semi-definite heteroskedasticity and autocorrelation-consistent covariance matrix. Econometrica, 55, 703-708.

Pesaran, M. H., and Potter, S. M. (1997). A floor and ceiling model of US Output. Journal of Economic Dynamics and Control, 21, 661-695.

Raymond, J. E., and Rich, R. W. (1997). Oil and the macroeconomy: A Markov state-switching approach. Journal of Money, Credit, and Banking, 29, 193-213.

Sichel, D. E. (1993). Business cycle asymmetry. Economic Inquiry, 31, 224-236.

Sichel, D. E. (1994). Inventories and the three phases of the business cycle. Journal of Business and Economic Statistics, 12, 269-278.

Teräsvirta, T., and Anderson, H. (1992). Modelling nonlinearities in business cycles using smooth transition autoregressive models. Journal of Applied Econometrics, 7, S119-S136.

Tong, H. (1995). Non-linear Time Series. A Dynamical System Approach. Oxford: Clarendon Press. First published 1990.

Tong, H., and Lim, K. S. (1980). Threshold autoregression, limit cycles and cyclical data. Journal of The Royal Statistical Society, B 42, 245-292. 